\title{
El dispositivo del fantasma de Pepper: la intermedialidad y el efecto de presencia
}

Paula Rojas Amador

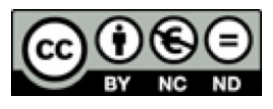

Esta obra está bajo una licencia Creative Commons Reconocimiento-No comercial-Sin Obra Derivada 
Artículos

\title{
El dispositivo del fantasma de Pepper: la intermedialidad y el efecto de presencia
}

\author{
Paula Rojas Amador \\ Universidad Laval, Canadá \\ paula.rojas.amador@una.cr
}

Recibido: 15 de octubre de 2016 Aprobado: 28 de octubre de 2016

\section{Resumen}

Este articulo tiene como objetivo el análisis de una de las técnicas de ilusión óptica más populares en el siglo XIX, conocida con el nombre de Pepper's Ghost o el fantasma de Pepper. Esta técnica es una de las precursoras en la utilización de la imagen virtual en la escena, motivando una discusión vigente en nuestros días, la relación entre la presencia virtual y la presencia "real" en el teatro. Para la comprensión de este dispositivo, nos referiremos a la técnica y los elementos que intervienen en su proceso, así como a los conceptos de intermedialidad y la noción de efecto de presencia.

Palabras clave: fantasma de Pepper; intermedialidad; efecto de presencia; presencia virtual y humana

\begin{abstract}
This article aims to analyze one of the most common popular optical illusion technique in the nineteenth century, known as Pepper's Ghost. This technique is one of the forerunners in the use of virtual image on the scene, prompting a discussion that has been extended until today, the relationship between virtual presence and the "real" presence in the theatre. For understanding of this apparatus, we refer to the technique and the elements involved in its process as well as, in the concept of intermediality and the effect of presence.
\end{abstract}

Keywords: Pepper's Ghost; intermediality; effect of presence; virtual and human presence 
La escena tecnológica desplaza la relación exclusiva entre el actor y el espectador e invita a una multiplicidad de presencias - sean estas sonoras, lumínicas, robóticas o visuales- a intervenir en el escenario con el actor. El mismo personaje puede no estar presente en la escena, pero estar presente para el espectador a través de un video, una llamada vía Skype, una grabación de voz, una llamada telefónica ${ }^{1}$. El actor ni siquiera requiere estar, hoy en día, en el mismo lugar del evento escénico, ni siquiera en el mismo país; por tal motivo, como afirma Pavis: "la présence n'est plus liée au corps visible [la presencia no está más vinculada al cuerpo visible]"2 (2007, p. 139) y aquí nos referimos a la presencia ligada a nuestra percepción, por lo tanto, al sentimiento producto de "notre condition originaire d'immersion dans le monde, en tant qu'expérience physique et corporelle [nuestra condición originaria de inmersión en el mundo, en tanto que experiencia física y corporal]" (Bourassa, 2013, p. 129).

Las nuevas tecnologías nos ofrecen posibilidades temporales, espaciales y estéticas que el teatro ha incorporado a la escena, de la misma manera que la sociedad se ha apropiado y familiarizado con las invenciones tecnológicas que lo rodean. Esta permeabilidad de las artes no es extraña, tal cual nos lo recuerda Luis Thenon: "las artes, han sido, a lo largo de la historia, el espejo en el que la sociedad ha visto reflejada la figura de su propia fisionomía, cambiante al ritmo de las tecnologías incorporadas al uso colectivo" (2010, p. 86). El teatro y las artes en general permanecen como laboratorio de esta época digital, así como de las anteriores. Según Pierre Morelli y Lucile Garbagnati, "si le théâtre interroge les technologies, en retour les technologies interrogent le théâtre et bien plus, l'humanité même de l'homme car, pour Plinio Prado, le corps est mis à l'épreuve du technologique [si el teatro interroga las tecnologías, en retorno las tecnologías interrogan al teatro y mucho más, la propia humanidad del hombre pues, para Plinio Prado, el cuerpo es colocado a prueba de la tecnología]" (2006, p. 7). Este mundo mediatizado visiblemente, puesto a prueba en la escena contemporánea, común para nosotros, es precedido por una serie de dispositivos visuales que han resistido, han evolucionado y se han transformado en el tiempo, entre los cuales podemos mencionar: la linterna mágica, la fotografía, la fantasmagoría, el ciclorama y el fantasma de Pepper. Con el fin de interrogar esta relación intermedial en la escena, hemos optado en este texto por el estudio del dispositivo de producción del fantasma de Pepper ${ }^{3}$, también conocido como Pepper's Ghost ${ }^{4}$.

\footnotetext{
${ }^{1}$ Véase (Pavis, 2007, pp. 138-140).

${ }^{2}$ Todas las traducciones son de la autora.

${ }^{3}$ Nos parece más adecuado utilizar la noción de "dispositivo de producción" del fantasma de Pepper, en lugar "dispositivo" concebido comúnmente como "disposición general de la escena" (Appia citado por Patrice Pavis, 2013, p. 63). El "dispositivo de producción" es propuesto por Jean-Pierre Sirois-Trahan y definido como: "el conjunto del estudio de producción y todas las operaciones que ahí se realizan. Por lo tanto, todo el conjunto material y de los procesos no intelectuales que forman el dispositivo material" (2003). Por lo tanto, el dispositivo de producción integra la parte material-técnica, la representación y el espacio. ${ }^{4}$ Esta reflexión tiene lugar en el marco del curso "Cinéma et intermédialité : Ville et visualité au 19e siècle.
} 
Esta técnica de ilusión óptica, el fantasma del Pepper, tiene como propósito generar "la presencia de un espectro", o sea, producir una "illusions de la vue, qui croit saisir une réalité là où il n'y a qu'une image [ilusión óptica, que nos hace creer que es real, eso que solamente es una imagen]" (Marion, 1867, p. 364). La presencia de un espectro, o, dicho de otra forma, la introducción de un cuerpo desmaterializado, no sólo influye en el aspecto técnico y estético de la escena, sino en la percepción del espectador. En el caso de nuestro dispositivo, el fantasma es considerado por el espectador como si estuviera presente en su mismo tiempo y espacio. Por esto, resulta importante señalar a este punto una diferencia sobre la relación con la imagen mediatizada entre el espectador de la mitad del siglo XIX y el espectador de hoy en día, cuya convivencia con la creación, construcción y recreación de la imagen es significativamente distinta.

Por esta razón, si para el espectador de la mitad siglo XIX, la aparición de un fantasma en la escena causaba un desconcierto, producía reacciones de admiración y miedo frente a lo desconocido, también era reconocida como un acto mágico, una ilusión. Por lo tanto, frases frecuentes, en los textos entre los años 1865 y 1903, como: "la ilusión es perfecta", "el arte inspirado por la ciencia", "una escena entre un fantasma y un ser vivo", "el efecto no deja ninguna duda en los espectadores de su posible realidad", "uno cree ver los fantasmas como objetos reales", nos indican el inicio de una gran controversia que continua hasta hoy: ¿Cuál es la relación entre lo real y lo virtual? No es casualidad que en los textos más recientes que cuestionan la hibridación entre los seres humanos y la tecnología, personajes virtuales y avatares, la presencia y el efecto de presencia, se mencione el dispositivo que estudiamos aquí como una de las primeras técnicas en esta orientación. A pesar de que, en nuestra era digital, la relación real-virtual es más significativa que en aquella época, el interés por este tema comenzó hace mucho tiempo.

Para discutir esta ilusión que suscita la presencia de un fantasma desde el punto de vista del espectador, la noción de efecto de presencia y la intermedialidad serán fundamentales para nuestra reflexión. El efecto de presencia es un concepto relativamente reciente desarrollado por el grupo Performativité et effets de présence, que se centra, entre otros temas, en "une nouvelle problématique concernant le rôle désormais déterminant de la présence que ce soit celle des personnages virtuels ou celle des acteurs sur scène [nueva problemática relativa al papel irrevocable y determinante de la presencia ya sea de personajes virtuales o de actores en el escenario]" (Effets de présence, 2012). Según Josette Féral, el efecto de presencia se trata de un

sentiment qu'a un spectateur que les corps ou les objets offerts à son regard (ou à son oreille) sont bien là, dans le même espace et le même temps que ceux dans lesquels il se trouve, alors qu'il sait pertinemment qu'ils sont absents [sentimiento que tiene un espectador en el que

Pré-cinéma, littérature et spectacles populaires “ impartido por el profesor Jean-Pierre Sirois-Trahan de la Universidad Laval, 2015. 
los cuerpos o los objetos presentados a sus ojos (o a sus oídos) están ahí, en el mismo espacio y en el mismo tiempo en que ellos se encuentran, a pesar de que él sabe sin ninguna duda que ellos están ausentes] (2012, p. 26).

Por lo tanto, esto nos lleva a pensar que, si la noción de "presencia" implica, para Féral, "la reconnaissance d'une possibilité d'absence [el reconocimiento de la posibilidad de la ausencia]" (2012, p. 11), en el caso de el efecto de presencia, esta ausencia es asumida por el espectador como presencia o mejor dicho, como una ilusión de presencia. Como lo afirma Renée Bourassa, "on parle alors d' 'effet' de présence pour décrire les procédés en cause dans l'induction du sentiment de présence chez le sujet en situation d'expérience médiatisée hablamos de 'efecto' de presencia para describir los procesos implicados en la inducción del sentimiento de presencia en el sujeto en una situación de experiencia mediatizada" (2013, p. 133). Actualmente, por ejemplo, es común aceptar que nuestra comunicación sea mediatizada por las redes sociales, el Skype, el teléfono, el correo electrónico. Por lo tanto, nosotros asumimos que esta presencia del otro, mediatizada y virtual es real ${ }^{5}$, no requerimos de la presencia del cuerpo "real" del otro en nuestro mismo espacio-tiempo para confirmar que fue establecida una comunicación, realidad muy diferente para la sociedad de mitad del siglo XIX.

En una escena teatral como la nuestra, el efecto de presencia nos permite establecer puntos de discusión sobre la transformación de la recepción del espectador en el tiempo frente a este dispositivo y sus remediaciones, concepto del que hablaremos más adelante. Asimismo, para el estudio de esta zona relacional presente en el dispositivo de producción del fantasma de Pepper, optamos por el concepto de intermedialidad. La intermedialidad nos propone un enfoque, una manera de ver las relaciones que se construyen y reconstruyen en este espacio mediatizado sin segmentarlo, sin dividirlo. La intermedialidad, según Freda Chapple y Chiel Kattenbelt:

est un espace où les frontières s'estompent -et nous nous situons entre et à l'intérieur d'un mélange d'espaces, de médias et de réalités. Ainsi l'intermédialité devient un processus de transformation de pensée et de processus où quelque chose de différent est forme à travers la performan$c e$ [es un espacio donde las fronteras se difuminan $-\mathrm{y}$ nosotros nos situamos entre $\mathrm{y}$ al interior de una mezcla de espacios, de medias y de realidades. Así la intermedialidad se convierte en un proceso de transformación del pensamiento y de los procesos donde alguna cosa diferente se forma a través de la representación] (2006 citada por Patrice Pavis, 2014, p. 152).

La intermedialidad nos cuestiona el entre-dos, lo que se crea en esta zona de diálogo constante entre los diferentes actores involucrados en el proceso, donde la relación entre ellos y la tecnología es esencial. De esta manera, el concepto de intermedialidad, y la noción del efecto de

\footnotetext{
${ }^{5}$ Véase Philip (2013).
} 
presencia, nos permite un enfoque integrador, relacional y complejo para el estudio de este tejido híbrido creado entre la tecnología y el humano presente en este dispositivo de producción.

\section{Contexto histórico}

La ilusión óptica del fantasma de Pepper se desarrolló a mediados del siglo XIX, precedida por una serie de dispositivos visuales como la linterna mágica, la fotografía y la fantasmagoría. Numerosos documentos dan testimonio de la popularidad del dispositivo del fantasma de Pepper, especialmente entre los años 1865 y 1903, durante los cuales varios autores dedicaron diversos capítulos de sus libros para explicar el fenómeno de esta ilusión óptica. Además, el tema tenía una gran y constante presencia en los periódicos de la época (Le Monde illustré, Le Magasin Pittoresque, Les Mondes, La Nature). Los textos identifican como creadores de esta invención a John Henry Pepper (1821 a 1900) y a Henry Dircks (1806-1873) en Londres y a Robin Henry (1803-1874) en París ${ }^{6}$.

John Henry Pepper fue un científico, inventor y profesor británico muy interesado en conocer y mostrar las últimas innovaciones tecnológicas de la época. En 1854 como director del Royal Polytechnic Institution, ${ }^{7}$ incentivaba en ese espacio exposiciones de diferentes dispositivos y proyecciones luminosas. En ese contexto, Henry Dircks, un ingeniero inglés, propuso su invención en 1858. Pero la idea fue mejorada por Pepper y llegó a ser conocida con el nombre de "Pepper's Ghost". De acuerdo con un texto escrito por Edmund H. Wilkie, en memoria del profesor Pepper, Dircks había presentado "an apparatus for producing an optical illusion representing a ghost, but the capabilities of this apparatus were so limited that is remained an ingenious idea... a curiosity..." for which no practical application could be found [un aparato para producir una ilusión óptica que representaba un fantasma, pero las capacidades de este aparato eran tan limitadas permaneciendo como una ingeniosa idea ... una curiosidad ... para la cual no se pudo encontrar ninguna posible aplicación práctica]" (Wilkie, 1900, citado por Hecht, 1993, p. 311).

${ }^{6}$ Entre los textos más relevantes en el contexto de nuestra investigación se incluyen el libro The True History of Pepper's Ghost (1890) del Profesor Pepper. El capítulo VI, "Spectres vivants et impalpables", en Magie et physique amusante (1877) de Robert Houdin. El capítulo X, "Les Spectres ", en L'optique (1867) de Fulgence Marion. Y el capítulo XVIII, “ Spectres “, en Instructions pratiques sur l'emploi des appareils de projection d'Alfred Molteni.

${ }^{7}$ El Royal Polytechnic Institution de Londres fue fundado en 1838 por W.M. Nurse y fue considerado en el siglo XIX como uno de los lugares más importantes y de mayor prestigio donde se realizaban proyecciones luminosas. 
Al parecer, la propuesta técnica de Dircks no había llamado la atención, pero para el Profesor Pepper, algunos ajustes serían suficientes para hacer de esta una invención relevante. Según Wilkie, "Pepper had seen the possibilities inherent in the invention and had put it 'in a suited for general public exhibition' before Christmas 1862 based on the novel A strange story [Pepper había visto posibilidades inherentes en la invención y la había 'adaptado para una exhibición pública general' antes de la Navidad de 1862 basada en la novela Una extraña historia]" (citado por Hecht, 1993, p. 311) del autor Edward Bulwer-Lytton (1803-1873). La primera vez que se presentó El fantasma de Pepper fue el 24 de diciembre de 1862, en el Royal Polytechnic Institution, siendo catalogada de manera exitosa.

En el texto L'optique, de Fulgence Marion, se menciona el nombre del holandés Henri Robin como el inventor del dispositivo del fantasma de Pepper, del cual Marion escribe: "celui qui l'a exécutée avec le succès le plus grand et avec une perfection qui rend lillusion complète, est M. Robin, le physicien du boulevard du Temple ... Il montrait déjà ses spectres, à l'étranger, dès 1847 [ese que ha ejecutado con gran éxito logrando una perfección completa de la ilusión, es el señor Robin, el físico del boulevard del Temple ... él ya mostraba sus espectros en el extranjero desde 1847]" (Marion, 1867, p. 375). Robin era conocido en París por la creación de espectros, cuya popularidad lo llevó en 1862 a inaugurar su propio teatro, con el nombre de "Salle Robin".

En 1863, en París, Pepper y Dircks presentan el dispositivo del fantasma de Pepper en el teatro Imperial del Châtelet con una excelente recepción. No obstante, los espectros eran presentados al mismo tiempo en Paris por Herni Robin. Según Mannoni, "Henri Robin les exhibe dans une salle 49 boulevard du Temple, mais c'est entre les mains d'un rival, le lanterniste anglais John Henry Pepper, que 'son' invention triomphe, sur la scène du théâtre impérial $d u$ Châtelet [Henri Robin los exhibe en la sala número 49 del boulevard del Templo, pero es en las manos de un rival, el linternista inglés John Henry Pepper, que 'su' invención triunfa sobre la escena del teatro Imperial del Châtelet] (1995, p. 236). Este encuentro inamistoso lleva a Robin a publicar, en 1864, en "El almanaque Le Cagliostro, donde él denuncia el plagio del cual ha sido víctima" (Manoni, 1995, p. 236). El funcionamiento técnico del dispositivo del fantasma de Pepper era de hecho muy similar entre los diferentes inventores, como veremos más adelante.

Este dispositivo ha sufrido reconstrucciones y actualizaciones influenciados por factores históricos, sociales, estéticos y tecnológicos, a los que denominaremos con el concepto de remediación propuesto por Jay Bolter y Richard Grusin. Para estos autores, la remediación es definida como: "a medium is that which remediates. It is that which appropriates the techniques, forms, and social significance of other media and attempts to rival or refashion them in the name of the real [un médium, es este que remediatiza. Es este que se apropia de las técnicas, 
las formas y las significaciones sociales de otros medios y que trata de rivalizar con ellos o de rehacerlos en nombre de la realidad]" (2000, p. 65).

En el caso del fantasma del Pepper, una de las principales remediaciones de hoy en día es el holograma cuya finalidad es crear una imagen en tres dimensioneses. El holograma es construido con tecnologías más recientes, remplazando el viejo sistema, pero conservando el mismo propósito. Entre otros ejemplos de remediación, también podemos citar el trabajo de Georges Méliès, quién utilizaba esta ilusión óptica en el teatro y en el cine. Por lo tanto, la remediación del dispositivo está presente al transitar de un medio a otro medio conservando su función esencial que es producir la presencia de espectros. Por ejemplo, en los espectáculos de teatro y películas La mansión del diablo (1896), y Los encantadores Alcofrisbas (1903), podemos encontrar fantasmas y la aparición y desaparición de los personajes como motor de la historia. También es posible encontrar este dispositivo en el Cabaret du Néant, un tipo de cabaret artístico en Paris fundado en 1892, parecido al famoso cabaret Chat Noir de Montmartre en Paris, que estimulaba el encuentro de artistas e intelectuales de la época, pero en un ambiente oscuro y misterioso. El dispositivo del fantasma de Pepper era de las principales atracciones, donde se producía la trasformación de un hombre en esqueleto a través de una superposición de la imagen, pero esta vez con algunas modificaciones de la técnica original. El mismo principio utilizado en el Cabaret du Néant ha sido utilizado largamente en los festejos populares en América Latina, donde una de las famosas atracciones es una mujer que se convierte en gorila.

Actualmente en Quebec, la compañía artística multidisciplinaria Lemieux-Pilon 4D-Art es una de las compañías que utiliza ampliamente la presencia de espectros ${ }^{8}$. Como afirma

Figura 1. Icare, concepción y puesta en escena de Michel Lemieux et Victor Pilon

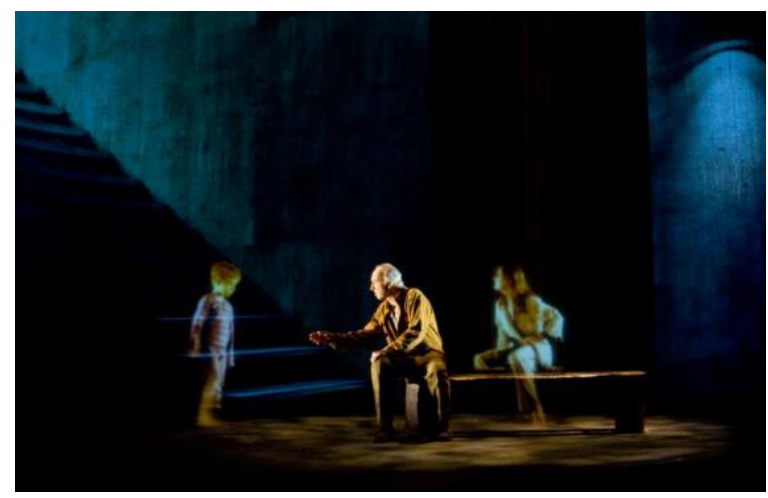

Fuente: Imagen facilitada por la compañía de teatro Lemieux Pilon 4D Art, mediante una comunicación personal,
Figura 2. La Belle et la Bête, concepción y puesta en escena de Michel Lemieux et Victor Pilon

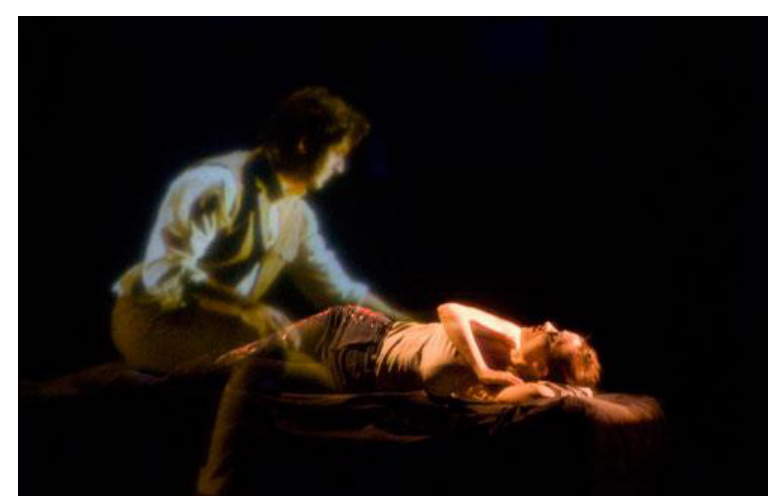

Fuente: Imagen facilitada por la compañía de teatro Lemieux Pilon 4D Art, mediante una comunicación personal. 
Michel Lemieux: "nous utilisons donc l'illusion du Pepper's Ghost afin de créer un langage qui, audelà de l'évolution de la technologie, permet de rendre visible ce qui est normalement invisible sur scène [nosotros utilizamos la ilusión de Pepper's Ghost con el objetivo de crear un lenguaje que, más allá de la evolución de la tecnología, permite hacer visible lo que es normalmente invisible en el escenario]" (Lemieux citado por Edwige Perrot 2013, p. 328). Siendo una de sus principales marcas como artistas, Lemieux-Pilon han explorado largamente esta técnica de ilusión en diversos espectáculos, entre ellos: Icare (2014), La bella y la bestia (2011), Norman (2007) y La Tempestad de William Shakespeare (2005).

\section{El funcionamiento del dispositivo de producción}

Figura 3. "Comment on produit les spectres", ("Cómo se producen los espectros")

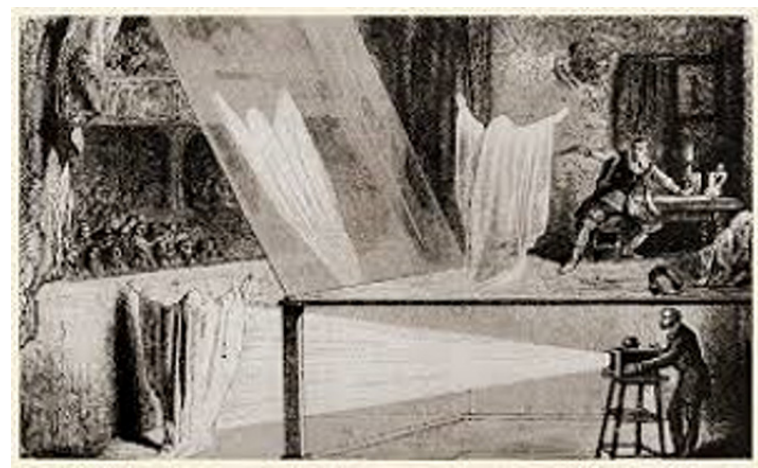

Fuente: Yves Renaud.

Partimos de la idea de que el dispositivo de producción del fantasma de Pepper es una técnica de ilusión óptica que sirve para producir "la presencia de un fantasma". En los textos consultados, hay un consenso sobre los requisitos y exigencias para colocar el dispositivo en marcha en el escenario. Los elementos esenciales para su producción son la linterna mágica (fuente luminosa); el actor que representa el fantasma y que está ubicado abajo del escenario y frente a un fondo negro; el actor "real"; la placa de vidrio que forma un ángulo de 45 grados con respecto al plano del teatro y también es posible mencionar el técnico (debajo de la plataforma) y un espacio obscuro o semi-obscuro. La disposición del espacio para la instalación del dispositivo debe considerar el lugar donde se encuentra el espectador, la escena y el espacio debajo del escenario en el cual se encuentra el técnico y el actor-fantasma, como se muestra en la figura $3^{9}$.

El dispositivo funciona cuando el actor-fantasma es iluminado por la linterna mágica o la fuente luminosa. Esta produce un rayo de reflexión en la placa de vidrio inclinada y el fantasma aparece a una distancia igual detrás de esta placa. Para que el efecto sea impecable, dos elementos son meticulosamente trabajados: el tratamiento de la placa de vidrio y el trabajo interpretativo.

\footnotetext{
${ }^{8}$ Véase. Sitio web de la Compañia Lemieux-Pilon 4art, http://4dart.com/fr/

${ }^{9}$ La imagen "Comment on produit les spectres" se encuentra en Fulgence Marion (1867).
} 
La placa de vidrio, según Robert Houdin "doit être d'une grande pureté d'exécution pour ne pas être vue des spectateurs [debe ser maniobrada con gran limpieza para que no sea vista por los espectadores]" (1877, p. 91) y, además, la dimensión del vidrio debe ser medida. La transparencia del vidrio permite ver los objetos detrás de él, por esta razón, la presencia del espectro no deja ninguna duda. Sobre el vidrio, Henry Pepper llama la atención a los diversos ajustes que deben ser realizados para conocer la inclinación correcta. Él indica que una persona debe observar desde la galería y que otra persona debe observar desde el foso del teatro, para indicar cuando pueden ver una imagen espectral precisa para proceder a los ajustes ${ }^{10}$. Además, la inclinación de la placa de vidrio depende de las características del espacio donde la escena tiene lugar.

Figura 4. Diagrama

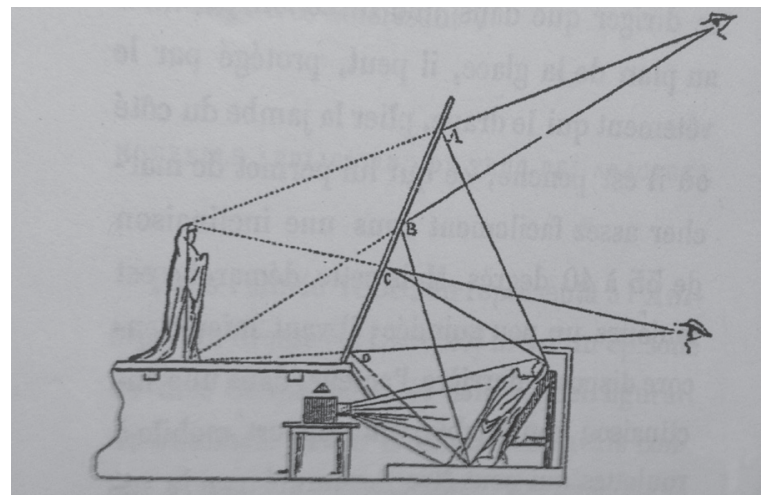

Fuente: Pepper, 1980, p. 95
Figura 5. Diagrams illustrating the "Ghost" Machinery [Diagramas ilustrativos de la maquinaria del "fantasma"]

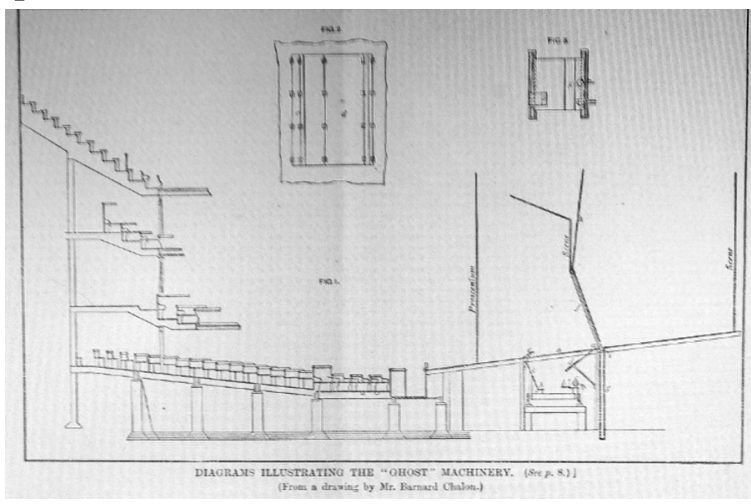

Fuente: Pepper, 1980, p. 10.

Cuando el fantasma aparece, el actor que está en el escenario no lo puede ver; por esta razón, la secuencia de movimientos que será ejecutada debe ser pre-establecida con el actor-fantasma. Como afirma Marion: "les mouvements sont réglés en sens inverse de ce qu'ils doivent être réellement. Par exemple, le zouave est forcé de tirer le sabre de la main gauche pour que ce soit la droite qui vienne se figurer dans la surface réfléchissante [los movimientos son ajustados en el sentido inverso de como ellos deberían ser realmente. Por ejemplo, el soldado se ve obligado a apuntar la espada con la mano izquierda para que sea la derecha la que aparezca en la superficie reflectante]" (1867, p. 380). La indicación de que el actor-fantasma debe ubicarse de forma paralela a la placa de vidrio inclinada, es también mencionada en los textos, aunque los textos de Houdin y Pepper evocan una estructura con una inclinación tal como se muestra

\footnotetext{
${ }^{10}$ Véase. (Pepper, John Henry, 1890, p. 8.).
} 
en la figura $4^{11}$, en el cual el actor-fantasma se coloca frente a la placa de vidrio inclinada, para producir así el efecto deseado.

Como los movimientos del actor están restringidos por la estructura, Houdin aconseja "un support mobile à roulettes qui peut être dissimulé par les vêtements du spectre ... il peut ... marcher en avant et en arrière dans la ligne suivie par le support [una estructura móvil con ruedas que pueda ser disimulada por el vestuario del espectro ... él puede ... caminar hacia adelante y hacia atrás en la línea en la que se encuentra la estructura" (1877, p. 96), lo cual facilitaría los efectos de desplazamiento y daría mayor realidad al espectro. Houdin también menciona que en "certains cas, l'acteur tient ses jambes immobiles, et le chariot sur lequel il est appuyé [est] tiré par une corde [algunos casos, el actor mantiene las piernas inmóviles, y la estructura en la que está apoyada [es] jalada con una cuerda]" (1877, p. 97).

El actor-fantasma está vestido de blanco y este color también ayuda a que la imagen sea reflejada. No obstante, es posible encontrar, en textos e imágenes, alusiones del actor ves-

Figura 5. Detalle de diagramas ilustrativos de la maquinaria del "fantasma"

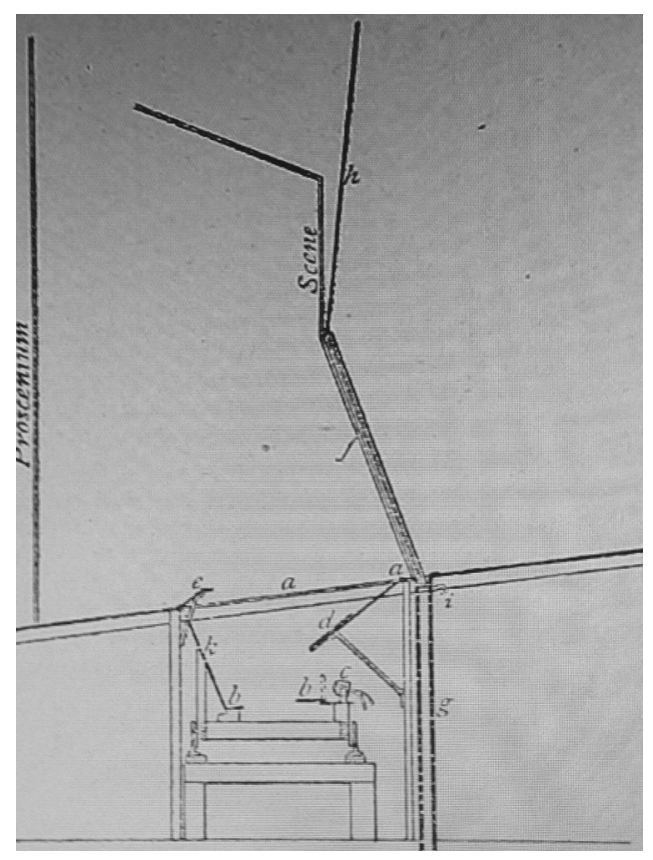

Fuente: Pepper, 1980, p. 9. tido con un traje de esqueleto. Otras dos consideraciones son destacadas para lograr el efecto deseado: la luz sobre la escena debe ser muy baja durante la aparición del fantasma para poder apreciar el efecto y el fondo detrás del actor-fantasma debe ser de color negro para evitar que otros elementos se reflejen al mismo tiempo que el espectro.

En el texto de Henry Pepper se destacan tres aspectos que merecen interés: las puertas falsas o las trampillas, la posibilidad que la placa de vidrio se eleve y los efectos deseados. Para explicar el procedimiento, nos vamos a apoyar en la ilustración de su libro (Fig. $5^{12}$ ).

En la ilustración, es posible observar el escenario, la orquesta, la galería y el espacio bajo la escena, lo cual se debe notar con atención (Fig. VI, detalle de la figura anterior). Las puertas falsas o trampillas ocultan la existencia de un lugar debajo del escenario, donde se encuentra el actor-fantasma, la linterna mágica y el técnico. Las puertas son indicadas en el anexo IV con las letras "e" y "d". La puerta falsa "e" sube y la otra puerta

\footnotetext{
${ }^{12}$ La imagen « Diagrams illustrating the "Ghost" Machinery" se encuentra en John Henry Pepper (1890).
} 
falsa "d" desciende. Las dos puertas se mantienen generalmente cerradas y el actor es libre de moverse, ya que se abrirán únicamente en el momento de la aparición del fantasma. Las puertas falsas o trampillas, según Pepper, "are covered with green baize or other dark material, so that when the trap doors are opened, the audience, even those in the gallery, will not readily be able to perceive the opening [están cubiertas con fieltro verde u otro material oscuro, de manera que cuando las trampillas se abren, el público, incluso los de la galería, no podrán, fácilmente, ser capaces de percibir la apertura]" (1890, p. 8.). Por otra parte, en la figura 4, las letras "f", "h" y "g" corresponden, respectivamente, a la placa de vidrio, la cuerda y al lugar donde se guarda el vidrio. En el texto, Pepper ofrece la opción de colocar de forma permanente la placa de vidrio durante todo el espectáculo o de colocarlo antes de la aparición del fantasma. Para el presente análisis, se considerará la segunda opción.

La placa de vidrio, indicada con la letra "f", se mantiene debajo del escenario, donde se encuentra la letra "g", y se sube con la ayuda de una cuerda, indicada con la letra "h", en un momento determinado, dividendo la escena en dos (Pepper, 1890, p. 10.). El autor sugiere que el actor pase, momentos antes de que la escena del fantasma aparezca, por el lugar donde será colocado la placa de vidrio, y según él, esto causaría mayor emoción entre los espectadores, ya que estarán convencidos de que no hay nada entre ellos y el actor. Pepper escribió: "then immediately the glass is run up, the trap doors are opened, the actor or image on the hidden stage is illumined and the phantom appears [inmediatamente el vidrio sale hacia arriba, se abren las trampillas, el actor o la imagen debajo del escenario es iluminada y aparece el fantasma]" (1890, p. 11). En cuanto a los efectos deseados, el espectro puede aparecer y desaparecer una o varias veces; este puede desaparecer poco a poco o puede desaparecer de repente. Para lograrlo, se utiliza la linterna mágica y las puertas falsas (Pepper, 1890, p. 9).

Estos detalles técnicos utilizados en la versión de Peppers y Dircks son revelados en el texto de Pepper, así como en el texto de la patente en la Encyclopédie Pre-cinema History. Si las técnicas más sofisticadas como las trampillas, la elevación del vidrio o el juego con la luz y el fantasma se llevaron a cabo, en las presentaciones del fantasma de Pepper durante esa época, fuera del contexto de estos textos, no es posible verificarlo. Sin embargo, este hecho no resta valor a la existencia de un pensamiento complejo y estratégico para producir en el espectador el efecto deseado.

En la actualidad, diversas variaciones del dispositivo original han sido recreadas: por ejemplo, la linterna mágica fue sustituida por el proyector; el actor fantasma fue remplazado por una imagen, por un video o podría ser trasmitido en directo por una cámara; también, un monitor podría ser utilizado para producir el reflejo en el vidrio o en el plexiglass. Existen modificaciones como la utilizada en el Cabaret du Néant, o en las fiestas populares, en 
donde, para superponer la imagen, utilizan el mismo principio del dispositivo original, pero con la diferencia de que el dispositivo se encuentra ubicado en un mismo nivel, en lugar de dos niveles como se anotó anteriormente. En el caso del holograma, el alto costo y complejidad del dispositivo lo ha hecho menos atractivo para la escena.

\section{La intermedialidad y la noción de efecto de presencia}

Una vez analizado el funcionamiento del dispositivo de producción, es importante retomar el concepto de intermedialidad, para examinar el tejido de las relaciones entre los diferentes actores presentes en esta ilusión óptica. A primera vista, existe una relación directa entre la linterna mágica y el actor-fantasma que está siendo iluminado. También, es posible hallar una relación entre el actor-fantasma iluminado y la placa de vidrio producida por el reflejo de los rayos sobre el vidrio, y otra conexión entre el vidrio y la imagen producida. Además, hay una otra correlación entre la imagen producida y el actor en la escena, sin olvidar la relación entre el espectáculo y el espectador requerida para generar en él, el juego de la ilusión, incluyendo la imagen producida y el espectador (el efecto de presencia).

Asimismo, es necesario mencionar una relación un poco más compleja entre la ficción de los personajes del actor que interpreta el fantasma y del actor en la escena, y la relación del fantasma entre dos mundos, o entre dos espacios que él coloca en contacto. Vale la pena profundizar dos de las relaciones que se han identificado: la relación del actor con la ficción del personaje y el efecto de presencia producido por la relación establecida entre la imagen del fantasma y el espectador.

De hecho, el trabajo del actor, en general, se basa en el juego de las apariencias. O sea, se trata de simular ser un otro distinto a sí mismo. La palabra griega "hypokrité" revela el significado esencial del trabajo del actor. En el dispositivo de producción del fantasma de Pepper, como de costumbre, el actor se presenta ante el espectador bajo la apariencia de un personaje, una ilusión, una ficción, un ser ficcional construido por el mismo actor. No obstante, este actor interpreta su papel frente a un fantasma que solo el espectador puede ver; este actor ni siquiera puede ver el actor que interpreta el fantasma que está bajo la escena, ni percibe el juego interpretativo que el reflejo del actor-fantasma le propone, por lo tanto, ninguno de los dos percibe el actor con el que ellos deben interactuar. Ambos deben utilizar su imaginación para ajustarse al juego escénico. Como escribe Beatriz Picon-Vallin, "la coexistence des différents registres de présence implique une tension entre corps vivants et corps dématérialisé, propice là encore au développement de l'imaginaire [la co-existencia de diferentes registros de presencia implica 
una tensión entre cuerpos vivos y cuerpos desmaterializados, propiciando además el desarrollo de la imaginación]" (1998, p. 29).

Los dos actores interpretan su secuencia de lucha como si fuera la realidad. De este modo, dichos actores se encuentran en una mediación de las relaciones, en primer lugar, a través de la ficción y, en segundo lugar, a través la presencia del fantasma. En el teatro es usual trabajar con objetos imaginarios y en ocasiones con personajes imaginarios, pero la relación con la imagen virtual es menos común. Actualmente, para la producción de diversos juegos de video, hay un amplio campo de trabajo para los actores, ya que son requeridos para interactuar con personajes imaginarios o imágenes virtuales para la creación de los mencionados videojuegos, lo que hace esta interacción con lo invisible, para los actores, más frecuente.

Asimismo, en una entrevista con los directores de la compañía 4D Michel Lemieux y Victor Pilon ${ }^{13}$, ellos explicaron el proceso de preparación del actor y la presencia virtual en sus espectáculos, ya que, de la misma manera que el dispositivo original, el actor no puede ver con quien interactúa. Según lo conversado, durante el trabajo de mesa y los primeros ensayos, todos los personajes -sin importar su rol (real o virtual) - son presentes, como sucedería en un montaje tradicional. Posteriormente, el actor que interpreta el personaje virtual ensaya todo vestido de negro con el actor que va a estar en la escena, hasta finalmente ser remplazado por la imagen virtual. En el caso de los directores Lemieux-Pilon, estos utilizan un video y no el actor en directo, como en el dispositivo original. Para ellos, el actor requiere de esta preparación previa para lograr darle credibilidad y humanidad a la interacción propuesta entre cuerpo real y cuerpo virtual, interacción que tiene reglas técnicas-espaciales, de juego y estéticas, que deben ser consideradas por el actor

La relación entre espectador y espectáculo, es sin duda, fundamental en el teatro; no podemos imaginarnos un teatro sin espectadores. El teatro nace en la confrontación con el espectador y de la disponibilidad y generosidad imaginativa de este último, con la que los actores sacan ventaja para jugar en el escenario. Como lo afirma Renné Bourassa:

En considérant sa fonction sémiotique, tout dispositiffictionnel a le potentiel de créer des effets de présence par le passage qui institue une présence réelle là où il y a une absence: Hamlet n'est pas vraiment sur scène, l'illusion de sa présence provient d'un acte sémiotique que le spectateur construit à partir des signes scéniques, que ce soit par la médiation du corps de l'acteur ou par le contexte fictionnel qu'installe la théâtralité. Autrement dit, tout rapport fictionnel au monde repose sur un effet de présence [Considerando su función semiótica, todo dispositivo ficcional tiene el potencial de crear efectos de presencia por el paso que instituye una presencia real ahí donde hay una ausencia: Hamlet no está realmente en la escena, las ilusiones de su

\footnotetext{
${ }^{13} 11$ de junio de 2015, comunicación personal.
} 
presencia provienen de un acto semiótico que el espectador construye a partir de los signos escénicos, sea por la mediación del cuerpo del actor o por el contexto ficcional que instala la teatralidad. Dicho de otra manera, toda relación ficcional en el mundo reposa sobre un efecto de presencia] (2013, p. 139).

En el caso de nuestro dispositivo de producción, mediante la creación de un cuerpo presente pero intangible, se desea provocar en el espectador la sensación de que el fantasma es y se mueve como un ser humano, llevándolo a asumir como si estuviera presente en su propio espacio y esto, a pesar de que el espectador sabe que está ausente. Esto es el efecto de presencia. Tambiém existen otras prácticas contemporáneas a las que Josette Féral hace referencia:

Certaines installations scéniques qui recourent au virtuel (les spectacles de la compagnie 4D-Art de Michel Lemieux et Victor Pilon, les installations de Janet Cardiff ou les chorégraphies de Stéphane Gladyszewski, par exemple). Celle-ci visent précisément à créer des apparences de présence ... et aspirent à susciter chez le spectateur une expérience d'un genre particulier, qui se fonde sur une impression qu'il y a du vivant sur scène alors qu'il sait pertinemment qu'il n'y a personne et que ce qu'il voit est le simple effet de l'illusion qui trompe ses sens. Dans ce cas, l'impression de présence vient de ce que le spectateur éprouve, en l'absence d'un sujet, quel qu'il soit, les mêmes sensations et perceptions que si ce sujet était effectivement dans l'environnement immédiat [Algunas instalaciones escénicas que utilizan lo virtual (los espectáculos de la compañía 4D-Art de Michel Lemieux y Victor Pilon, las instalaciones Janet Cardiff o las coreografías de Stéphane Gladyszewski, por ejemplo). Tiene como objetivo la creación de presencias aparentes [...] y aspiran a producir en el espectador una experiencia de tipo particular, que se basa sobre la impresión de que hay vida en el escenario cuando él sabe que no hay nadie y que lo que él ve es el simple efecto de la ilusión que engaña sus sentidos. En este caso, la impresión de presencia viene por lo que el espectador experimenta, en la ausencia de un ser, sea cual sea, las mismas sensaciones y percepciones que si este ser estuviera de hecho en el entorno inmediato] (2012, p. 13).

Si bien la esencia del dispositivo - tanto en el pasado como en la actualidad-continúa siendo la producción de la ilusión, la recepción del espectador se ha modificado. Por esta razón es importante destacar que el efecto de presencia, tal cual lo percibimos hoy en día, requiere la plena conciencia por parte del espectador de que esa imagen que aceptamos como "real" es producto de la mediatización, por tato se trata de una realidad distinta para el espectador del siglo XIX. Por lo tanto, esta relativización perceptiva debe ser tomada en cuenta en el análisis del dispositivo.

Es decir, el teatro parece ser un lugar perfecto para el encuentro con lo que no existe en la realidad. Un lugar de diálogo entre los mundos y los tiempos, un espacio que puede crear diversas identidades y que ofrece la posibilidad de viajar al pasado o al futuro; un espacio de creación y de transformación. La presencia de lo real y de lo virtual puede llevar a pensar en la especificidad del teatro, en el rol del actor, en la relación del actor y la imagen y en los procesos 
creativos y en las modificaciones que las nuevas tecnologías producen en estos procesos, en el espectador y en la sociedad actual.

"El actor", afirman Morelli y Garbagnati, "détient la réponse, non seulement pour apprivoiser les technologies mais pour interroger les rapports entre fiction, réel, actuel et virtuel. Il mobilise la corporalité, garante de l'humanité intrinsèque du champ théâtral [tiene la respuesta, no solamente para perfeccionar las tecnologías, pero para interrogar las relaciones entre ficción, realidad, presente y virtual. Él moviliza la corporalidad, garantiza la humanidad intrínseca del campo teatral]" (2006, p.7). Considerar las repercusiones e influencias que una ilusión óptica como el dispositivo del fantasma de Pepper, entre otras, podría haber generado, en nuestra percepción del mundo, implicaciones perceptivas que la robótica o la realidad virtual tienen y tendrán en un corto plazo en la escena teatral contemporánea.

Por lo tanto, la posibilidad de analizar la manera cómo funciona el teatro desde una perspectiva intermedial -la cual permita visualizar la interacción y los intercambios entre todos sus elementos- es aún más enriquecedor; en este sentido, tal y como afirma Pavis "notre perception est entièrement déterminée par l'intermédialité nuestra percepción es totalmente determinada por la intermedialidad" (2014, p. 139). Al largo de estas páginas, se ha intentado comprender el dispositivo de producción del fantasma de Pepper a través de nuestros ojos, nuestra época, nuestra experiencia, pero al mismo tiempo se ha visualizado la manera en la cual este dispositivo era considerado en la época de su concepción. La transformación de este dispositivo de producción del cual se ha expuesto una reflexión técnica, estética, social e histórica que conduce hasta la actualidad. Él es, por excelencia, un dispositivo intermedial de actualidad y un antecedente de la relación actual con lo virtual. Esta hibridación entre lo real y lo virtual iniciada durante el siglo XIX es presente y es capaz de accionar temas que se discuten hoy, relativas a las nuevas tecnologías en el arte.

\section{Referencias}

Bolter, J. D.; Grusin, R. (2000). Remediation: Understanding New Media. Cambridge: MIT Press.

Bourassa, R. (2013). De la présence aux effects de présence. En Le réel à l'épreuve des technologies : les arts de la scène et les arts médiatiques (pp. 129-147). Rennes: Presses Universitaires de Rennes.

Effets de présence. (2012). Présentation du groupe de recherche. Recuperado de https://effetsdepresence.uqam.ca/

Féral, J. (2012). Pratiques performatives: Body Remix, Québec: Presses Universitaires de Rennes. 
Féral, J. (2013). Le réel à l'épreuve des technologies: les arts de la scène et les arts médiatiques. Rennes: Presses Universitaires de Rennes.

Hecht H. (1993). Pre-cinema history: An encyclopaedia and annotated bibliography of the moving image before 1896. Londres: Bowker Saur.

Houdin, R. (1877). Spectres vivants et impalpables: Apparitions fantastiques. En Magie et physique amusante (pp. 79-112.). Paris: Calmann Lévy.

Mannoni, L. (1995). Le Grand Art de la lumière et de l'ombre: archéologie du cinéma. Paris: Nathan.

Marion, F. (1867). Les spectres. En L'optique (pp. 364-380). Paris: Libraire de L. Hachette et C.

Molteni, A. (1892). Spectres. En Instructions pratiques sur l'emploi des appareils de projection: Lanternes magiques, fantasmagories polyoramas (pp. 212-214). Paris.

Morelli, P. y Garbagnati, L. (2006). Thé@tre et nouvelles technologies. Dijon: Éditions Universitaires de Dijon.

Pavis, P. (2007). La mise en scène contemporaine: origines, tendances, perspectives. Paris: Armand Colin. Pavis, P. (2014). Dictionnaire de la performance et du théâtre contemporain. Paris : Armand Colin.

Pepper, J. H. (1890). The true history of the ghost, and all about metempsychosis. Londres, Paris, New York: Cassell \& Co.

Perrot, E. (2013). Le performeur virtuel : Parcours dans l'œuvre 4D Art par Michel Lemieux. En Personnage virtuel et corps performatif: effets de présence (pp. 321-337). Québec: Presses de l'Université du Québec.

Picon-Vallin, B. (1998). Hybridation spatiale, registres de présence. En Les écrans sur la scène (pp. 9-35). Lausanne: Éditions L'Âge d'homme.

Philip, Auslander. (2013). Le direct numérique: perspective historico philosophique. En Josette Féral yEdwige Perrot (eds.), Le réel à l'épreuve des technologies: les arts de la scène et les arts médiatiques (pp. 61-72). Rennes: Presses Universitaires de Rennes

Sirois-Trahan, JP. (2003). Dispositif(s) et réception. Cinémas: Revue d'études cinématographiques, 14(1), 149-176.

Thenon, L. (2010). Una Modernidad Extrema. Tempestad, (72), 86-89. 